\title{
On Green Strategy: Effect on Automotive Industry of Pakistan
}

\author{
Muhammad Ahmed Butt ${ }^{1}$, Paul Katuse ${ }^{1} \&$ Juliana M. Namada $^{1}$ \\ ${ }^{1}$ United States International University-Africa, Nairobi, Kenya \\ Correspondence: Muhammad Ahmed Butt, Doctor of Business Administration (Candidate), United States \\ International University-Africa, P. O. Box 14634-00800. Nairobi, Kenya. E-mail: info@usiu.ac.ke
}

Received: November 27, 2017

Accepted: December 20, 2017 Online Published: January 15, 2018

doi:10.5539/ijbm.v13n2p221

URL: https://doi.org/10.5539/ijbm.v13n2p221

\begin{abstract}
The purpose of this paper is to examine the green management and sustainable growth operations interventions specifically in the automotive industry perspective. Existing literature on green management and sustainable development has been studied with special focus on green strategy in the automotive industry as explored in the environmental-oriented research in respect of the selected automotive firms. The research unfolds the prodigious concern witnessed among the world governments, international agencies and policy decision-makers in global firms, related to green economy, green management and green strategy in order to achieve triple bottom-line impact. Paradoxically, the dominant automotive players have different green strategies for developed and developing economies. Approaches, internalizing the strategic decision-making, range from proactive to reactive. The investigation leads to a focus on main environmental initiatives and issues in the automotive industry of Pakistan. Significant improvement is needed to tackle environmental concerns and to acquire the catalyst effect of green management interventions to abate and reverse the damage already done to environment. The study of Pakistan may offer value for researchers and practitioners for further research in green management and green strategy in national industry context.
\end{abstract}

Keywords: green management, green strategy, sustainable development, automotive industry

\section{Introduction}

The conceptual framework of green economy is contingent upon recognition of factual paradigms forces, holistically integrated in social, economic, socio-economic and environmental development strategies, serving as catalyst for sustainable and environmental development [United Nations Environment Programme (UNEP), 2014]. It brings out the theme that jointly political commitment in the focal area of economic, and social development, may provide impetus for productive extrinsic and intrinsic results. Harrison (2008) took a strong position and asserted that global business is in the ambit of corporate greening 2.0; the underlying factors focused on economic, social, coupled with political facets. Porter (1996) aptly argued that strategy is the construction of valuable and distinct position in the competitive arena. Essentially, a green strategy is about organization's strategic decisions that result into positive impact on the overall environment. Olson (2008) asserted his position that green strategy strives to leverage key decisions deeply anchored in the both concrete business logic and business prudence. Babiak and Trendafilova (2011) presented the contextual frame of reference viz. the determinants of environment based strategies on the continuum ranging from reactive to proactive green management dimensions.

In the backdrop of literature and researchers' studies grounded into green management theories, the paper explores the perspectives of international agencies, governments and corporate world on the theme of environmental sustainability focusing on automotive industry, being of a strategic importance for world economies, for output and employment creation. The paper studies green management interventions ranging from green strategy to implementation and proactive to reactive approaches in the automotive industry of both the triad (i.e. Japan, Europe and USA), and Pakistan to provide useful insights viz. crafting green strategy for automotive industry of Pakistan; however generalizability may not be inferred.

\section{Green Management Strategy}

The concept of green economy is deeply rooted into the interrelation among distinctly inclusive factors like: environmental consideration, trade/businesses growth, and social well-being as reflected in the newly evolved development models [International Institute for Sustainable Development (IISD), 2014]. The United Nation's 
2030 Agenda for Sustainable Development has committed to resolution among nations to design a policy and implement it in a coherent manner supporting environment for sustainable development at all tiers by all players. The Sustainable Development Goals (SDGs) targets and the means to achieve them through pragmatic policy are termed as Enhance Policy Coherence for Sustainable Development (PCSD). The PCSD is about challenges particularly for international development and developing mechanism for effective governance. The [Organisation for Economic Co-operation and Development (OECD), 2009] Assistance Committee (DAC) sought to harmonize in manageable ways the competing policy goals by establishing concrete institutional models referred as Policy Coherence for Development (PCD); the building blocks having three critical components. Firstly, at political level, unwavering commitment coupled with policy statements to internalize the policy and transpose it into implementable practices. Secondly, putting mechanisms in place to remove bottlenecks in smooth policy coordination and mitigate deviation in implementation, and finally, developing programs having inbuilt monitoring systems to take informed strategic decisions after performing impact analysis on solicited information/data. OECD (2009) maintained that by having institutional mechanism, developing nations make steady progress in the direction of realizing their aspirations in sustainable development.

Pew Charitable Trusts (2009) conducted study in the US; consistent with its inferred findings, enactment of federal clean energy \& climate bill had the inherent potential to provide substantial impetus to adopt new green technology innovations and have positive impact intangibly in creating new jobs in incremental way. Mckinsey, the consulting firm conducted Global Survey (2007); it was ostensible from the empirical research that 2,687 chief executives officers (CEOs) envisaged that climate change will receive the paramount critical importance with public deliberations on the topic and entail key decision-making regarding environment. In this vein it will have direct bearing on the business and corporate plans.

Scholars and researchers in their recent literature objectively maintained this position and argued logically that green management strategies are meaningfully relevant to achieve success in broader areas of industries (Clarkson et al. 2011) leading the firms in the direction of realizing the competitive position and advantage (Berchicchi et al. 2012). It is ironical to witness that notwithstanding the growing concern and relevance of environmental sustainability inclusive of corporate social responsibility in the current economic scenarios (Garzella \& Fiorentino, 2014), strategic decision-making models suffer from circumscribed empirical studies (Dahlmann et al. 2008). In the realm of currently existing literature it can be construed that a practical and result-oriented framework to cater the compelling environmental strategies is lacking (Babiak \& Trendafilova, 2011). In the wake of this emerging situation, (Epstein, 2010) emphasized the growing need to construct new approaches. Elkington (2004) presented the triple bottom line (TBL) perspective geared toward generating added value by mobilizing and leveraging the strength of critical resources including effective utilization of capital. Roberts and Cohen (2002) referred to this concept as triple value adding (i.e. people, planet, and profit).

In the face of multiple daunting challenges and considering the fact that governments' resolve toward sustainable development is not to be undermined; their leadership role among various spheres of green management and adapting clean energy technologies is imperative too. To substantiate this argument [United Nations Industrial Development Organization (UNIDO), 2013] in its report aptly concluded that governments have to design incentives to help finance new green technology change requirements supported with well-articulated implementable policies with reinforcing government's result-based leading role with futuristic vision.

\section{Theoretical Perspective}

\subsection{On Strategy}

Porter (1996) argued at length and presented conceptual theme of strategy. Consistent with Porter's views, strategy is building unique position with valuable different set of activities which come underplay to create strategic position. Briefly, this strategic position emerges, firstly where many customers' few needs are best served; few customers' broad needs are catered; broad needs of host of customers are taken care of in a narrowly positioned market; secondly, strategy is contingent upon making trade-offs in competing activities. And finally, strategy entails establishing 'fit' in organization's critical activities.

A different conceptual perspective of strategy is forwarded by Kim and Mauborgne (2005); the theory is termed as blue ocean strategy. Interestingly blue ocean strategy is logically counter intuitive thinking; it is by no means having a thrust on the technology innovation. According to authors the blue oceans are hardly a result of technological innovation criteria. Supporting their theoretical determinant, the authors elaborate that technology already exists in the dynamic market; blue ocean strategic planners create its linkage with buyers' needs and value. Additionally, creating blue oceans does not mean venturing into waters which are away in terms of 
distance. Quite often than not, in majority cases, blue oceans are carved out from within provided area. Kim and Mauborgne (2005) reiterated and put emphasis that industry players invariably create blue oceans by leveraging the competencies in the core areas of current businesses. In the final argument of the authors, strategists entrusted with crafting blue ocean strategy negate treating competition as a benchmark; they contrive the competition irrelevant by developing a leap forward in value. The crux of blue ocean strategy, therefore is, (i) developing market space having no competition and remaining unchallenged by the competitors;(ii) strategically fighting the battle, making the competition insignificant;(iii) more importantly; developing new demand and capitalizing on it; dismantling the value/cost related to trade-off. And finally, aligning the complete system, the business model of a firm's operational activities, with bottom-line impact in creating differentiation and resulting in low cost (Kim \& Mauborgne, 2005). Some researchers maintained that competitive strategy generates both extension and competing contexts. Porter (1998) aptly maintained the position that with the awareness of the critical importance of strategy, competitive strategy has acquired special place in the broader spectrum of management and has lent a reinvigorated perspective to integrated view of competition.

\subsection{On Green Strategy}

Olson (2008) endeavored to capture the theme of a green strategy. In this case, the author's underpinning concept about green strategy is that it leverages and provides impetus to firm's operations and asset strategies of the business; those are invariably well crafted by the enterprise. In his view the concept applies to all types of enterprises including public and commercial; private and multinationals and so forth. A green strategy extends concrete support to an enterprise to make informed decisions which in turn bring about significant positively-driven environmental impact. The tenets of a green strategy provide credence to firm in taking informed decisions grounded in logical substance and entrepreneurial sense. Olson (2008) observed that in the green strategy, the idea to infuse logical and business-oriented sense is grounded into three dogmas. These three doctrines will serve as three principles for crafting green strategy at enterprise level. Essentially these three tenets include, firstly, a green strategy helps in fostering uniform culture having force to create awareness and action-oriented components; secondly, a green strategy determines the strategic decisions coupled with transformational interventions having potential to impact the environment in improved ways; and finally, a green strategy has determinant substance for attractiveness in terms of value propositions and cost effectiveness. Figure 1 presents Olson's (2008) three tenets of green strategy.

A Green

Strategy
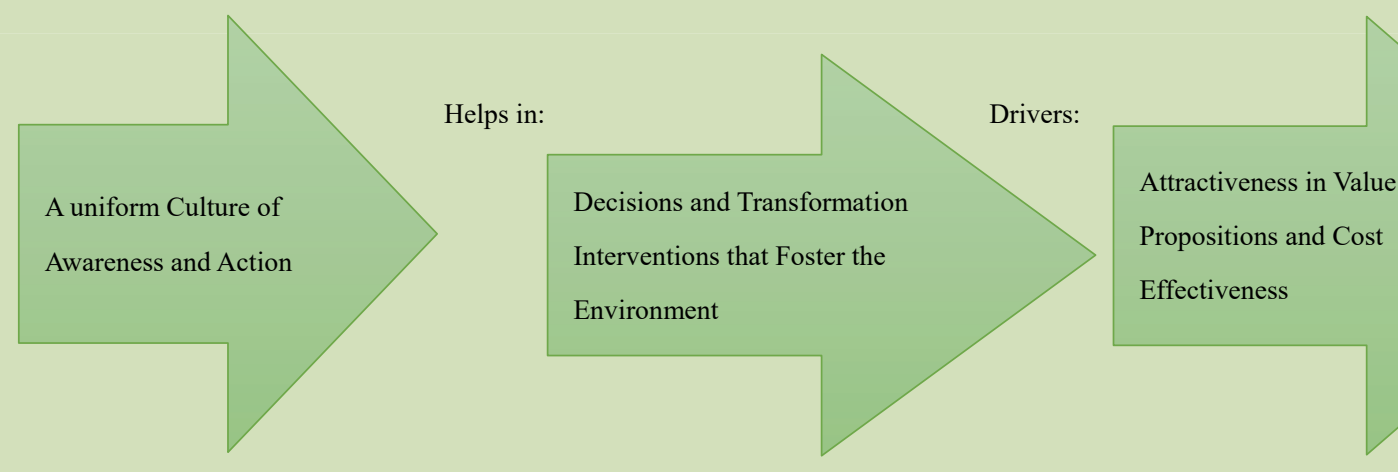

Drivers:

Developing employees' daily work activities, reflecting common culture where environment awareness and proactive behavior is normal credo.

- Stakeholders in the firm to be equipped with proper tools and training toward organization culture to help make their stay rewarding with ease and fun.
- The environment should be consolidated with existing criteria to provide facilitation in decision-making.

- $\quad$ Priorities indicated by green strategy need proper integration with corporate, business and operational strategies including asset. This way prioritized strategies may align and resolve conflicting interest.

Figure 1. Three Tenets of Green strategy

Source: Creating an enterprise-level "green" strategy, Olson, G.E. (2008) 
Intensity of interest is witnessed in the study by (Perego \& Hartmann, 2009) where emphasis is placed on aligning organizational practices and making them congruent with strategic direction of the firm. Array of literature and studies documented that without developing and internalizing logical and systematic strategic models of green management, organizations remain at disadvantage and will be incapacitated to transform productive environmental outcomes into meaningful realization of financial bottom-line (Clarkson et al. 2011). In macro context, environmental strategies may be characterized as whole organization recognizing the compelling importance thereof; and realizing the legitimacy linked with biophysical environment, in crafting the corporate strategy, and operationalizing environmental facets by integrating and incorporating the same into the strategic techniques being followed (Banerjee, 2001). In this vein, environmental strategies endorse admitting and grounding the environmental dogma and doctrine in strategic management processes and literature (Sharma \& Enriques, 2005; Lee \& Rhee, 2007). In the literature, Orsato (2006) contributed and presented generic style environmental strategies having competitiveness at core, including (i) eco-efficiency; (ii) environmental cost leadership; (iii) beyond compliance leadership, and (iv) eco-branding. Incidentally, it is objectively construed that Orsato (2006) strategy framework is identical to Porter's (1980) generic strategies of driving competitive advantage i.e. low cost vis-à-vis differentiation.

\subsection{Environmental Strategy Determinants}

By and large two broad perspectives of research have been witnessed in research studies with thrust on the environmental strategy and its strategic drivers (Dahlmann et al. 2008). The first and foremost driver is anchored in the socio-institutional context; it presents that organizations internalize the green management thoughts to help keep the threats like liabilities and compliance cost concerning legislations at the minimal level (Khanna \& Anton, 2002).

The second driver which has its roots in the resource-based view (RBV) theoretical perspective of the organization, argued when it boils down to strategic considerations between environmental and financial performance, there is no trade-off (Ansoff, 1984; Berry \& Rondinelli, 1998). Lately Siegel (2009) presented framework on green management executing practices which have economic and strategic contextual themes. Sprengel and Busch (2011) spelt out the underlying concept that profit-driven organizations ought to engage in green management system not for mere fact of social and moral grounds but more importantly because action-based response to bonafide desires of stakeholders to implement environmental designed actions/practices has resultant positive impact on performance of the firm. It is conclusive to infer that various perspectives of research, in part, shed light on the drivers of environment-driven strategies and logically it can vary along the spectrum ranging; that is from reactive green management to proactive green management approaches as paradigm (Babiak \& Trendafilova, 2011).

\section{Automotive Industry Context}

\subsection{Generic Perspective}

The statistics reported by Organization International des Constructeurs d'Automobiles (OICA), 2010), indicate that approximately 78 million vehicles (i.e. cars and commercial vehicles) were manufactured, in 2010, globally; and subjectively evaluated that new direct jobs to the tune of 8 million were created in the field of assembly facilities and components/parts development. This constitutes 5 percent of industrial-based employment opportunities worldwide. The statistical report further mentions that European Union (EU) have above one fourth of contribution in the manufacturing output. The [Association des Constructeurs Européens d'Automobiles (ACEA), 2011]; report based on 2007 figures indicated that 3.5 million jobs were created, which was 10.2 percent of total industrial related jobs and accounted for 5.6 percent of total employment of the EU. In United States (US) context, Hill et al. (2010) pointed out that the manufacturing base of vehicles in US is portrayed as considerably large. The 2008 statistical analysis in respect of US provided this insight that this sector's contribution was around 3 percent in the gross domestic product (GDP). This key sector created 1.7 million direct jobs in the industrial sector and in terms of indirect jobs the documented figure goes beyond 8 million. Similarly, around 4.5percent jobs were generated in the private sector due to automotive industry in US.

Orsato and Wells (2007b) highlighted automotive industry challenges in the areas of economic component, environmental dimension and operational bottlenecks. The authors categorically defined that progressive manufactures of cars in particular are bracing daunting challenge viz. three technological business models i.e. cars manufactured with all-steel bodies, engines (type internal combustion), and (hybrid) vehicles. Ironically these car manufacturing firms believe in pursuing the implementation norm inclining toward incremental tactics-based improvement. It is further stressed by the authors that prevalent dynamic political and volatile economic inter-connectivity of automotive industry with related sectors, for instance the oil industry, create 
further constraints in introducing and/adopting drastic innovation in order to achieve the optimal level in environmental programs performance. William (2007) argued that the compelling and daunting challenges faced by automobile industry get aggravated due to the inter-dependencies existing between auto industry and other segments of the economy. The author deliberated at length to seek depth and breadth of sustainability concept in automobile sector by way of looking deeply at systemic perspective at operational side and more importantly in the business model inclusive of owning a car and product support systems.

Nunes and Bennett (2010) advocated in their study that vehicle manufacturing firms must face a crucial fact realistically i.e. the customers may give preference to the idea of driving greener cars, but in their purchasing decision-making process green specifications of features contribute minor consideration. Rothenberg et al. (2005) recommended benchmarking related to environment for automotive players encompassing four classifications namely (i) compliance with legislation; (ii) efficiency (iii) gross emissions level, and (iv) analysis relevant to product life-cycle. In an empirical study, Hahn et al. (2008) objectively evaluated sixteen (16) groups engaged in automotive manufacturing and assessed them based on the sustainability criteria. The authors conclusively inferred from the findings of the study that two automotive groups (i.e. Toyota and BMW) are dominant players vis-à-vis competitors in sustainable value context. Regarding supply chain management (SCM) Koplin et al. (2007) provided comprehensive details on systems of measures with underpinning goal to offer key sustainability criteria in the field of SCM. In the case study of Volkswagen Group, the authors demonstrated the different dimensions of SCM policy and its cascading effect on various strategic operational parameters. Gernuks et al. (2007) carried out research study focusing on environmental facets of operational actions in Volkswagen with a view to explicitly conceptualize the tangible contribution made in the areas like manufacturing facilities site, body \& paint shops, assembly line at the plant, and other related operational factors including critical environmental facets. It implies that there are various tools to perform the SCM measurement including environmental balanced scorecard nonetheless, according to Hervani et al. (2005) it is still a challenging endeavor to effectively perform green SCM measurement in realistic context.

\subsection{Automotive Green Examples}

In 2008, in the triad countries (i.e. Japan, Europe and USA) the dominant automotive players with global presence included firms like: Toyota (Japan), General Motors (GM) USA, and Volkswagen (Germany). Nunes and Bennett (2010) carried out a study primarily making use of already generated literature attempting to draw conclusions as to how these three largest automotive firms in triad block are undertaking environmental interventions particularly in the western world, and how they are making the strategic moves to confront challenges viz. environment-specific issues. The authors (Wells \& Orsato, 2005; Williams, 2006, 2007) studied and in their objectively based narrative presented the case that small size firms are better poised in internalizing and implementing interventions and reflecting advancement possessing originality in terms of nature.

Nunes and Bennett (2010) drew these inferences from analysis that the dominant progressive manufacturers of cars in the world have started integrating environmental theme in the operational programs and its continuum ranges from constructing manufacturing facilities to completion of product-life-cycle. In addition, the authors shed light on the fact that certification related to green building was enforced both at manufacturing plant facilities and non-production plant sites. Toyota and GM commenced capitalizing on the opportunities and leveraged the mechanism in place to patronize the green-based power and successfully endeavored switching from oil consumption at the plant to use of solar energy, gas (landfill), wind energy, and using green-based power initiatives in the automotive firms substituting $\mathrm{CO} 2$ emissions with cleaner fossil fuels technology.

Through Nunes and Bennett (2010) study, it transpired that these automotive firms undertook variety of other green-based initiatives to achieve the desired objectives concerning environment. Pragmatic approaches are in practice among these car makers and in this direction progress is witnessed; for example, introducing lightweight material in the design, fuel efficiency, reducing and/or eliminating the volatile organic compounds (VOCs) and putting the intelligent programs to control road traffic pollution. New stringent end-of-life vehicle (ELV) legislation and recycling are given serious consideration in automotive industry. These triad countries players are cultivating the power of technology-oriented systems to resolve the environmental related critical challenges. It is worth noting that implementing prevalent stringent ELV legislations may be considered as learning ground for automotive players in the triad countries to gain knowledge, competencies and much needed experience, and this result-driven pool of experience will serve as profound argument for newly emerging economies and green management agencies enact new legislations. Global players of automotive sector may be at an advantageous position and may logically become a role model in meaningfully executing operational activities in presence of stern environmental legislation, and will probably act as leading catalysts in terms of: operational and strategic holistic system to maintain their formidable position worldwide. Nunes and Bennett (2010) research apparently 
reflects that Toyota, GM and Volkswagen having operation in the triad block are embarking on to move strategically from reactive to proactive green environment strategy and reinforcing their span of control in both up and down streams strategic operation of the firm

\subsection{On Pakistan Perspective}

The economy of Pakistan has historically exhibited uncertain growth trajectory leading to country's unstable economic conditions Ministry of Finance [Pakistan Economic Survey (PES), 2016-17]. GDP growth is around 5.28 percent in 2016-17. Notwithstanding reasonable gains documented in economic areas, there remain key domains which need improvement i.e. balance of payments, and the export-import imbalance. In manufacturing sector automotive industry contributed 17.02 percent in the year 2015. Vehicles production stood at around 822 thousand in the year 2015. It is estimated in the [Engineering Development Board (EDB), 2016] report that by 2019 the automobile industry's production will experience a hike to the tune of 1.4 million units. According to [Japan International Cooperation Agency (JICA), 2011] report, in Pakistan, progressive manufacturing of automotive products are based on full-line manufacturing including cars(Honda, Toyota and Suzuki), buses, trucks, rickshaws, and tractors, serving small market with smooth incremental impact. Despite a long history of operation, the industry is dominated by labor-intensive assembly shops and is lacking in locally made automotive parts, and modern production plants. For local cluster of suppliers it is a daunting challenge to come at par with international quality parameters and standards. The underlying causes of inadequate quality standards are, among others; production capacity constraints, lack of innovative technology, and bottlenecks related to quality assurance (JICA, 2011).

Pakistan, like other developing nations is a signatory to various conventions including United Nations Framework Convention on Climate Change (UNFCCC); having adopted the convention Pakistan needs to internalize all the conventions covenants inclusive of its agendas and protocols. Ministry of Climate Change (MOCC) presented factual scenarios regarding greenhouse gases and emission related inventory perspective. In the year 2008 greenhouse gases (GHG) emissions were recorded as 310 million tons of $\mathrm{CO} 2$ in Pakistan. MOCC of Pakistan, in the [National Climate Change Policy (NCCP), 2012] report stressed that the underpinning factors of air pollution are, among others, phenomenal hike in the volume of automotive products coupled with the use of inappropriate automotive manufacturing technology. The total number of vehicles on road witnessed dramatic increase; in 1992 the vehicles on the road were 2.1 million units, however by 2003 the total number reached to 5 million units. And the year 2009 statistics recorded 9.4 million units and in terms of percentage the increase is around 450 percent comparing it with year 1992 figure (JICA, 2011).

Pakistan has developed interventions toward climate change and endeavoring to implement the obligation of United Nations Kyoto Protocol (1998) clean development mechanism (CDM) of UNFCCC; the bottom-line goals of CDM being to identify strategically cost-efficient strategies to reduce the negative implications surfaced due to climate change issue. Needless to say, it is one of the strategically determinant propositions to provide powerful source for the developing countries in realizing the defined goals related to green management. Pakistan's national operational strategy for clean development mechanism provides impetus to craft policy guidelines for effective execution of CDM in Pakistan consistent with sustainable development goals developed at national level. This strategy is incentive based and the underlying strategic context is to operationalize and establish the efficiency and transparency. The strategy's critical dynamics include designing and undertaking arrangement at instructional hierarchy for CDM implementation in Pakistan. Research literature is inadequate to construe the true picture of green management strategy and its implementation in the automotive industry viz. initiatives both in terms of the automotive industry players' operations and policies as well as the legislation introduced by the Government of Pakistan (GOP) related to automotive industry. Even multinational firms like: Honda, Toyota and Suzuki are battling with quality issues viz. parts suppliers manufacturing standards; and missing out on the modern plant facilities in Pakistan (JICA, 2011). The dearth of available research and literature indicates explicitly the capacity issues confronted by the GOP in realizing the underpinning importance of sustainable based development and green management in the automotive sector of the economy.

\section{Discussion}

Objectively and rationally explained narrative about the concept of green economy is deeply rooted into the interplay of environmental consideration, trade/businesses growth, and strategic thinking construct. Green economy is based on uniform social, economic, socio-economic and environmental development strategies; having the potential to lead to environmental development in sustainable manner [United Nations Environment Programme (UNEP), 2014]. In the similar vein, Harrison (2008) stressed that global business is in conjecture with corporate greening 2.0, with focus on economic, social development coupled with political component. 
Porter (1996) who is considered to be authority on competitive strategy has provided insight that strategy is the construction of valuable and unmatched position in the competition. Talking about green strategy, it is different from corporate strategy; green strategy is a conceptual perspective and implies taking organization's strategic decisions in a manner that the outcomes have positive impact on overall environment. To form a logical argument, scholars and researchers substantiated their point of view by emphasizing that green strategies crafted with green management elements create high probable connotation to lead toward success in all the industries (Clarkson et al. 2011) thereby leading the firms in the direction of realizing the competitive advantage (Clarkson et al.2011;Berchicchi et al. 2012). In the wake of daunting challenges, Government's role cannot be undermined to mitigate negative impact emerging from the negation of green management.

The various dimensions of a green strategy provide consolidated support to an enterprise to opt for informed decisions and adopt environmental policies/strategies. The doctrines that constitute ground for green strategy leading a business to decision-making are deeply grounded into business logic (Olson, 2008). In the similar context; environment based strategies acknowledge the fact that environmental policy has to be infused in strategic management processes and literature. It is fair to infer that drivers of environmental-driven strategies may experience variation from a reactive green strategic dogma to proactive green dogma (Babiak \&Trendafilova, 2011). It is conclusive to interpret that strategic mechanisms to abide by stringent environmental legislation have the substance to serve as learning grounds for the triad countries automotive players; their result-driven pool of experience may serve to the advantage of developing nations governments to pass green management related new legislations. Dominant global automotive players may play lead role in disseminating acquired knowledge to overcome the environmental challenges, this way may additionally maintain superiority in the competitive arena.

Pakistan economy is characterized by uneven growth trajectory. According to MOCC of Pakistan, automotive products are the major source of air pollution, and the situation gets further deteriorated due to deficiency in terms of modern technology in the automotive sector in Pakistan. It is ironical to note that global firms, for example, Honda, Toyota and Suzuki are struggling with quality issues. Available literature and research point toward the issues confronted by the GOP in realizing the underpinning importance of sustainable development as green management is not addressed in a scientific manner and automotive industry is not an exception.

\section{Conclusion}

Green economy is optimally ingrained in a logical interplay of given set of drivers (i.e. environment, trade/businesses, and developing strategic thinking) to construct doctrines to realize the sustainable development goals. Inevitably, as studies and literature highlights that sustainable development framework includes social-oriented theme, economic perspective, and environmental development); nonetheless the absence of pragmatic and result-oriented green management conceptual framework makes the environment development complex in scale. Formulating sound green strategy and perfect execution is afflicted with intriguing peculiarities such as inherent conflict of interest among different stakeholders' perceptual perspectives viz. the explicit short and long term benefits, with the resultant impact that governments and corporate world is less receptive to trade-offs particularly in developing countries including Pakistan. Additionally, environmental issues' importance gets undermined as green management decision-making models remain inconclusive due to lack of proper research studies in this field. The situation gets further complex as current body of knowledge is inadequate and fails to offer comprehensive framework to cater to growing demand for crafting green strategies.

It is logical to infer from this paper that in the triad countries, automotive players are strategically internalizing the green strategy at their modern plants, gradually progressing toward proactive approaches to realize the sustainable development goals. The same automotive players whilst having operations in developing economies, like Pakistan, pursue a green strategy based on reactive determinant without specific green strategy models. The host government apparently lacks meaningfully conceived sustainable development strategies for automotive industry and supporting mechanism for stringent green strategy enforcement. Research based well thought out green economy policy design at governmental level, and corporate firms' paradigm shift from reactive to proactive determinant may provide impetus for automotive sector of Pakistan to become competitive internationally and contribute positively toward making the country growth-oriented in a sustainable manner particularly in the key automotive industry.

\section{References}

Ansoff, I. H. (1984). Implanting Strategic Management. Englewood Cliffs, NJ.: Prentice Hall.

Association des Constructeurs Européens d'Automobiles. (2011).The automobile industry pocket guide (2011). Retrieved from http://www.acea.be/uploads/publications/pocket_guide_2011.pdf 
Babiak, K., \& Trendafilova, S. (2011). CSR and environmental responsibility: motives and pressures to adopt green management practices. Corporate Social Responsibility and Environmental Management, 18(1), 11-24.

Banerjee, S. B. (2001). Corporate environmental strategies and actions. Management Decision, 39(1), 36-44.

Berchicchi, L., Dowell, G., \& King, A.A. (2012). Environmental capabilities and corporate strategy: Exploring acquisitions among US manufacturing firms. Strategic Management Journal, 33(9), 1053-1071.

Berry, M. A., \& Rondinelli, D. A. (1998). Proactive corporate environmental management: A new industrial revolution. Academy of Management Executive, 12(2), 38-50.

Clarkson, P. M., Li, Y., Richardson, G. D., \& Vasvari, F. P. (2011). Does it really pay to be green? Determinants and consequences of proactive environmental strategies. Journal of Accounting \& Public Policy, 30(2), 122-144.

Dahlmann, F., Brammer, S., \& Millington, A. (2008). Environmental management in the United Kingdom: new survey evidence. Management Decision, 47(2), 264-283.

Elkington, J. (2004). Enter the triple bottom line. In A. Henriques \& J. Richardson (Eds.), The triple bottom line: Does it all add up? (pp. 1-16). London, England: Earth scan.

Engineering Development Board. (2016). Automotive development policy (ADP) 2016-2021. Retrieved from http://www.engineeringpakistan.com/

Epstein, M. J. (2010). The challenge of simultaneously improving social and financial Performances: New research results. Emerald Publishing, Bingley.

Garzella, S., \& Fiorentino, R. (2014). An integrated framework to support the process of green management adoption. Business Process Management $\quad$ Journal, $\quad 20(1), \quad 68-89$. https://doi.org/10.1108/BPMJ-01-2013-0002

Gernuks, M., Buchgeister, J., \& Schebek, L. (2007). Assessment of environmental aspects and determination of environmental targets within environmental management systems (EMS) e-development of a procedure for Volkswagen. Journal of Cleaner Production, 15(11/12), 1063-75.

Green, D., \& McCann, J. (2011). Benchmarking a leadership model for the green Economy. Benchmarking: An International Journal, 18(3), 445-465. https://doi.org/10.1108/14635771111137804

Hackstone, D., \& Milne, M.J. (1996).Some determinants of social and environmental disclosures in New Zealand companies. Auditing, Accounting and Accountability Journal, 9(1), 77-108.

Hahn, T., Figge, F., \& Barkemeyer, R. (2008). Sustainable Value in Automobile Manufacturing: An Analysis of the Sustainability Performance of Automobile Manufacturers Worldwide. Retrieved from http://www.sustainablevalue.com

Harrison, E. B. (2008). Corporate Greening 2.0: Create and Communicate Climate Change and Sustainability Strategies. Publishing Works, Exeter, NH.

Hervani, A., Helms, M., \& Sarkis, J. (2005). Performance measurement for green supply chain Management. Benchmarking: An International Journal, 12(4), 330-53.

Hill, K., Menk, D., Gregger, L., \& Schultz., M. (2010). Contribution of the Automotive Industry to the Economies of All Fifty States and the United States. Center for Automotive Research. Retrieved from http://www.cargroup.org/publications

International Institute for Sustainable Development. (2014). The state of sustainability initiatives review (2014). Retrieved from https://www.iisd.org/pdf/2014

Japan International Cooperation Agency. (2011). Project for Automobile Industry Development Policy in the Islamic Republic of Pakistan Main Report. Retrieved from http://open_jicareport.jica.go.jp

Khanna, M., \& Anton, W. R. (2002).Corporate environmental management: Regulatory and market-based incentives. Land Economics, 78(4), 539-558.

Kim, W. C., \& Mauborgne, R. (2005). Blue ocean strategy: How to create uncontested market space and make the competition irrelevant. Boston, Mass.: Harvard Business School Press.

Koplin, J., Seuring, S., \& Mesterharm, M. (2007).Incorporating sustainability into supply management in the automotive industry - the case of the Volkswagen AG. Journal of Cleaner Production, 15(11/12), 1053-1062. 
Lee, S. Y., \& Rhee, S. K. (2007). The change in corporate environmental strategies: a longitudinal empirical study. Management Decision, 45(2), 196-216.

McKinsey Quarterly. (2007). How companies think about climate change: A Mckinsey Global Survey. Retrieved from $\mathrm{http} / / / \mathrm{www}$.washburn.edu/faculty/rweigand/mckinsey

Ministry of Climate Change. (2011-2012). Greenhouse Gas Emission Inventory of Pakistan. Retrieved from http://www.gcisc.org.pk/ghginventory2011-2012

Ministry of Climate Change. (2012). National Climate Change Policy Report 2012. Retrieved from http://www.gcisc.org.pk/national_climate_change_policy_2012

Ministry of Finance. (2016-17). Pakistan Economic Survey Report (2016-2017). Retrieved from http://www.finance.gov.pk/survey/chapters_17/overview_2016-17

Nunes, B., \& Bennet, D. (2010).Green operations initiatives in the automotive industry: An environmental reports analysis and benchmarking study. Benchmarking: An International Journal, 17(3), 396-442. https://doi.org/10.1108/14635771011049362

Olson, E. G. (2008). Creating an Enterprise-Level “Green” Strategy Journal of Business Strategy, 29, 22-30.

Organisation for Economic Co-operation and Development. (2009). Building Blocks for Policy Coherence for Development (PCD) 2009. Retrieved from https://www.oecd.org/pcd/44704030.pdf

Organisation Internationale des Constructeurs d'Automobiles. (2010). 2010 production statistics. Retrieved from http://www.oica.net/category/production-statistics/2010

Orsato, R. J. (2006). Competitive environmental strategies: when does it pay to be green? California Management Review, 48(2), 127-143.

Orsato, R., \& Wells, P. (2007b). The automobile industry \& sustainability. Journal of Cleaner Production, 15(11/12), 989-993.

Perego, P., \& Hartmann, F. (2009). Aligning performance measurement systems with strategy: The case of environmental strategy. Abacus, 45(4), 395-428.

Pew Charitable Trusts. (2009). The Clean Energy Economy: Repowering Jobs, Businesses, and Investments across America. Retrieved from http://www.pewtrusts.org/en/research-and-analysis/collections/2010

Porter, M. E. (1980). Competitive Strategy. Techniques for Analyzing Industries and Competitors. New York: Free Press.

Porter, M. E. (1996). What is Strategy? Harvard Business Review, 61-78.

Porter, M. E. (1998). The Competitive Advantage: Creating and Sustaining Superior Performance. NY: Free Press.

Ringo, J. (2010). Clean energy already paying off. US News \& World Report, 8.

Roberts, B., \& Cohen, M. (2002). Enhancing sustainable development by triple value adding to the core business of government. Economic Development Quarterly, 16, 127-137.

Rothenberg, S., Schenck, B., \& Maxwell, J. (2005). Lessons from benchmarking environmental performance at automobile assembly plants. Benchmarking: An International Journal, 12(1), 5-15.

Sharma, S., \& Enriques, I. (2005). Stakeholder influences on sustainability practices in the Canadian forest products industry. Strategic Management Industry, 26(2), 159-180.

Siegel, D. S. (2009). Green management matters only if it yields more green: An economic/strategic perspective. Academy of Management Perspectives, 23(3), 5-16.

Sprengel, D. C., \& Busch, T. (2011). Stakeholder engagement and environmental strategy - the case of climate change. Business Strategy and the Environment, 20(6), 351-364.

United Nations Environment Programme. (2014). Trade and Green Economy (3rd ed.). Retrieved from http://web.unep.org/sites/unep.org.greeneconomy

United Nations Industrial Development Organization. (2013). Industrial Development Report 2013. Retrieved from https://www.unido.org/sites/default/files/2013-12/UNIDO

United Nations. (1998). Kyoto Protocol to the United Nations Framework Convention on Climate Change. Retrieved from https://unfccc.int/resource/docs/ 
United Nations. (2015). Addis Ababa Action Agenda. 2030 Agenda for Sustainable Development. Retrieved from http://www.un.org/esa/ffd/ffd3/press-release

Wells, P., \& Orsato, R. J. (2005). Redesigning the industrial ecology of the automobile. Journal of Industrial Ecology, 9(3), 15-30.

Williams, A. (2006). Product-service systems in the automotive industry: the case of micro-factory retailing. Journal of Cleaner Production, 14(2), 172-184.

Williams, A. (2007). Product service systems in the automobile industry: contribution to systems innovation? Journal of Cleaner Production, 15(11/12), 1093-103.

\section{Copyrights}

Copyright for this article is retained by the author(s), with first publication rights granted to the journal.

This is an open-access article distributed under the terms and conditions of the Creative Commons Attribution license (http://creativecommons.org/licenses/by/4.0/). 